\title{
Antegrade or Retrograde Approach for the Management of Tandem Occlusions in Acute Ischemic Stroke: A Systematic Review and Meta-Analysis
}

\section{OPEN ACCESS}

Edited by:

Panagiotis Papanagiotou, Bremen-Mitte Clinic, Germany

Reviewed by:

Lukas Meyer

University Medical Center Hamburg-Eppendorf, Germany Anastasios Mpotsaris, München Hospital, Germany

*Correspondence: Liqun Jiao

liqunjiao@sina.cn

Wenhuo Chen

13806906089@126.com

tThese authors have contributed equally to this work and share first authorship

Specialty section:

This article was submitted to Endovascular and Interventional

Neurology,

a section of the journa

Frontiers in Neurology

Received: 27 September 2021 Accepted: 08 November 2021

Published: 12 January 2022

Citation

Min X, Du J, Bai X, Wei T, Dmytriw AA,

Patel $A B$, Zhang $X, X u X$, Feng $Y$, Wang $T$, Wang $X$, Yang $K$, Hu W, Yi T, Chen $W$ and Jiao $L$ (2022) Antegrade

or Retrograde Approach for the Management of Tandem Occlusions in Acute Ischemic Stroke: A Systematic

Review and Meta-Analysis.

Front. Neurol. 12:757665.

doi: 10.3389/fneur.2021.757665

\begin{abstract}
Xiaoli Min ${ }^{1,2+}$, Jianhua $\mathrm{Du}^{3+}$, Xuesong Bai ${ }^{2,4 t}$, Tao Wei ${ }^{5}$, Adam A. Dmytriw ${ }^{6}$, Aman B. Patel ${ }^{6}$, Xiao Zhang ${ }^{2,4}$, Xin $\mathrm{Xu}^{2,4}$, Yao Feng ${ }^{2,4}$, Tao Wang ${ }^{2,4}$, Xue Wang ${ }^{7}$, Kun Yang ${ }^{8}$, Weiwu $\mathrm{Hu}^{9}$, Tingyu $\mathrm{Yi}^{10}$, Wenhuo Chen ${ }^{10 *}$ and Liqun Jiao ${ }^{2,4,11 *}$
\end{abstract}

${ }^{1}$ Department of Cerebrovascular Diseases, The Second Affiliated Hospital, Kunming Medical University, Kunming, China, ${ }^{2}$ Department of Neurosurgery, Xuanwu Hospital, Capital Medical University, Beijing, China, ${ }^{3}$ Peking Union Medical College, Chinese Academy of Medical Sciences, Beijing, China, ${ }^{4}$ China International Neuroscience Institute (China-INI), Beijing, China, ${ }^{5}$ Library, Kunming Medical University, Kunming, China, ${ }^{6}$ Neuroendovascular Program, Massachusetts General Hospital, Harvard Medical School, Boston, MA, United States, ${ }^{7}$ Medical Library, Xuanwu Hospital, Capital Medical University, Beijing, China, ${ }^{8}$ Department of Evidence-Based Medicine, Xuanwu Hospital, Capital Medical University, Beijing, China, ${ }^{9}$ Department of Neurology, The First Traditional Chinese Medicine Hospital of Chengde, Chengde, China, ${ }^{10}$ Department of Neurology, Zhangzhou Affiliated Hospital, Fujian Medical University, Fuzhou, China, " ${ }^{1}$ Department of Interventional Neuroradiology, Xuanwu Hospital, Capital Medical University, Beijing, China

Background: Acute ischemic stroke (AIS) caused by tandem intracranial and extracranial occlusions is not rare. However, optimal strategy between antegrade (extracranial first) or retrograde (intracranial first) approaches still remains elusive. This systematic review and meta-analysis aim to compare the two approaches to provide updated clinical evidence of strategy selection.

Methods: PubMed, Ovid, Web of Science, and the Cochrane Library were searched for literature comparing antegrade and retrograde approaches for patients with AIS with concomitant tandem occlusions. Outcomes including successful reperfusion [Throbolysis in Cerebral Infarction (TICl) 2b-3] and 90-day favorable outcome [modified Rankin Scale (mRS) 0-2], any intracerebral hemorrhage, symptomatic intracerebral hemorrhage, procedural complications, and mortality were evaluated. The risk of bias was assessed using the Newcastle-Ottawa Scale and illustrated in the Funnel plot. Heterogeneity was assessed by $R^{2}$ statistic. Subgroup and sensitivity analyses were also performed.

Results: A total of 11 studies accounting 1,517 patients were included. 831 (55\%) patients were treated with an antegrade approach and 686 (45\%) patients were treated with the retrograde approach. A higher successful reperfusion rate was achieved in retrograde group than that of antegrade group [83.8 vs. $78.0 \%$; odds ratio (OR): 0.63 , 95\% Cl: 0.40-0.99, $p=0.04$ ]. 90-day favorable outcome (mRS 0-2 at 90 days) also showed significantly higher in retrograde group compared with antegrade group (47.3 vs. $40.2 \%$; OR: $0.72,95 \% \mathrm{Cl}: 0.58-0.89, p=0.002)$. The incidence of any intracranial hemorrhage $(\mathrm{ICH})$, symptomatic intracranial hemorrhage, 90-day mortality, and other complications did not differ between two groups. 
Conclusion: In AIS with tandem occlusions, the retrograde approach might achieve a higher successful reperfusion rate and better functional outcome with a comparable safety profile when compared with an antegrade approach. Further prospective controlled studies with more meticulous design and a higher level of evidence are needed to confirm these results.

Systematic Review Registration: "PROSPERO" database (CRD 42020199093), https://www.crd.york.ac.uk/PROSPERO/.

Keywords: antegrade approach, retrograde approach, tandem occlusions, acute ischemic stroke, meta-analysis

\section{INTRODUCTION}

Acute ischemic stroke (AIS) is a major contributor to global morbidity and mortality (1). AIS caused by tandem occlusions, including a proximal extracranial occlusion in conjunction with an intracranial occlusion is not rare and was reported to consist of $10-20 \%$ of all the patients with stroke $(1,2)$. But, the treatment for this unique subgroup of patients is challenging. Achieving successful reperfusion is still the primary goal of treatment and will increase the likelihood of favorable functional outcomes. Previous studies have shown that the rate of reperfusion via intravenous tissue plasminogen activator (IV tPA) alone may be unsatisfactory $(3,4)$. Recently, the superiority of mechanical thrombectomy (MT) over IV tPA was established by clinical evidence from a series of randomized controlled trials (RCTs) $(1,5,6)$. Thus, MT has been the first-line choice of treatment.

For AIS with tandem occlusions, MT plus emergent carotid artery stenting could achieve a considerably high chance of reperfusion and functional independence $(7,8)$ and thus, has been considered as an acceptable treatment modality $(9,10)$. Nevertheless, evidence for optimal order of treatment, including antegrade (extracranial first) and retrograde (intracranial first) approach, is still elusive and controversial. Although comparable outcomes between the two approaches were found in the previous meta-analysis by Wilson et al. (11) the majority of recruited studies were single armed lacking direct comparison data. Also, many studies with larger sample size and directly comparing the two approaches were published thereafter (1215). Some studies still showed comparable results between the two approaches $(13,14)$. In stark contrast, a better outcome of the retrograde approach was shown in some other studies $(12,15)$. Additionally, the retrograde approach was adopted as the prior choice in some centers with respect to its effectiveness and safety $(14,16)$. Therefore, it is necessary to summarize the current literature comparing the two approaches, thus providing updated clinical evidence of strategy selection and decision-making for this special group of patients.

\section{METHODS}

\section{Search Strategy and Eligibility Criteria}

This study is conducted according to the Preferred Reporting Items for Systematic Reviews and Meta-Analyses (PRISMA) guidelines (see online Supplementary Files 1, 2. PRISMA Checklist) (17). A literature search was performed to identify studies assessing patients of AIS caused by tandem lesions with treatment strategy of antegrade (extracranial first) or retrograde (intracranial first) approaches. We searched the following databases including PubMed, Ovid, Web of Science, and the Cochrane Library for eligible studies. The preliminary search terms, including stroke, large-vessel occlusion, acute ischemic stroke, tandem occlusion, internal carotid artery (ICA) occlusion, and MT, were utilized to capture all the studies eligible for inclusion. The search strategy was detailed in the supplementary material (see online Supplementary File 3. Search strategy).

Two reviewers (YF and $\mathrm{XZ}$ ) screened and selected the eligible studies independently. Any disagreements were resolved with the help of another more senior reviewer (XB). Studies were regarded as eligible if they met the following criteria: reporting both the antegrade and retrograde approaches for patients with AIS, with $\geq 70 \%$ stenosis or occlusion of the extracranial ICA and concomitant occlusion of the intracranial ICA and/or proximal middle cerebral artery (MCA); outcomes data were sufficient and reported separately, so as to compare the two approaches: RCTs and observational studies (cohort studies and case-control studies). Studies were ruled out if duplicates and review articles, no comparison between antegrade and retrograde approaches, insufficient information, patients were not eligible, only abstract published, and case reports. The antegrade approach is defined as proximal-todistal revascularization, with angioplasty and/or stenting of the extracranial lesion first, followed by intracranial thrombectomy, while the retrograde approach is defined as distal-to-proximal revascularization, with the treatment of the intracranial occlusion with MT first, followed by treatment of the extracranial ICA occlusion.

\section{Baseline and Outcome Data Extraction}

After the selection of studies, a standardized form was used for data extraction by one author (XZ) and rechecked by another author (YF). The main characteristics of included studies were extracted including authors and publication year, recruitment period, country and centers, study design, total sample size, number of each group of the patients, etiology, therapy strategy, and favorable strategy. The following baseline data from each study were collected: age, gender, the National Institutes of Health Stroke Scale (NIHSS) score at admission, the Alberta Stroke Program Early CT Score (ASPECTS) at admission, the proportion of patients treated with IV thrombolysis, site of occlusion, thrombectomy technique, and procedural 
duration (defined as the mean/media time from a puncture to final reperfusion).

Available data of outcome variables were also extracted including successful reperfusion (defined as TICI $2 \mathrm{~b}-3$ after endovascular treatment); favorable outcome/functional independence (defined as mRS $0-2$ at 90 days); symptomatic intracerebral hemorrhage ( $\mathrm{sICH}$ ) [defined as $\mathrm{ICH}$ on imaging and a minimum increase of four points on the NIHSS within $24 \mathrm{~h}$ postintervention in accordance with the second EuropeanAustralasian Acute Stroke Study (ECASS II) classification (18)]; any ICH (defined as symptomatic ICH or asymptomatic ICH); procedural complications (defined as any procedure- and devicerelated complication such as artery dissection, artery perforation, clot migration, embolization, stent deployment failure, or device malfunction); and mortality at 90 days.

\section{Assessment of Heterogeneity and Publication Bias}

Heterogeneity was measured with the $I^{2}$ statistic and the value of $I^{2}>50 \%$ was regarded as moderate-to-high heterogeneity depending on the pooled results (19). Subgroup analysis was conducted to explore the reasonable origins of heterogeneity on the condition that the results with high heterogeneity and a sufficient number of included trials. We tried to perform subgroup analysis based on publication year or ethnicity. Sensitivity analysis was also conducted to evaluate the effect of exclusion for the study with a high overall risk bias.

To qualitatively evaluate the risk of publication bias, two independent reviewers (XM and JD) assessed each article through the Newcastle-Ottawa scale (NOS), which was designed for observational studies quality assessment (see online Supplementary File 4. NOS scale) (20). Each domain of included studies was given a score on the risk of bias (see online Supplementary File 5. Study quality assessment). Then, quantitatively evaluated publication bias by the Begg's test and the Egger's test and funnel plot was illustrated in case of the included studies exceed 10 (21).

\section{Statistical Analysis}

Odds ratio (OR) with 95\% CIs were used to depict the dichotomous data of most baseline and outcome variables and mean differences (MDs) with 95\% CIs for continuous variables such as mean age, the NIHSS or the ASPECTS score, and mean time of puncture to reperfusion. Statistical significance is defined at $p<0.05$. Only in the case of there being sufficient effect size or sample size (at least three studies), outcomes data were pooled in meta-analysis. The software Revman 5.3 (The Nordic Cochrane Centre, Copenhagen, Denmark) and RStudio software (R-Tools Technology, Inc., Canada): the Nordic Cochrane Center; https://rstudio.com/products/rstudio. (version 4.0.4) (RStudio using "meta" and "metafore" packages) were used for statistical analyses.

\section{RESULTS}

\section{Selection and Characteristics of Studies}

A total of 1,907 articles were initially identified through main electronic database and references of related studies, of which
34 full-text articles were retrieved for assessment after duplicates were removed and title/abstract screened. Eventually, 11 studies that met our inclusion criteria were eligible for final analysis (12$15,22-28)$. All the included studies had more than one outcome indicator available that was presented separately for comparison analysis between the different treatment strategies. The selection process of studies and reasons for exclusion were detailed in a flow diagram (Figure 1).

The main characteristics of included studies and baseline data of patients were given in Tables 1, 2 and Supplementary File 6. All the studies were published between 2015 and 2021. Among them, five studies were retrospective single-center studies, one study was retrospective multicenter studies, and the remaining five studies were large multicenter cohort with retrospective review from the prospective collected database. Meanwhile, three studies were conducted in Asia country and the other eight studies were carried out by a research collaboration mainly in Europe or USA. A total of 1,517 patients (sample size from 17 to 493) with AIS and concomitant anterior circulation tandem lesion were enrolled including 831 (55\%) patients who adopted antegrade approach (extracranial treatment first or proximal-todistal revascularization) and $686(45 \%)$ patients who adopted retrograde approach (intracranial treatment first or distal-toproximal revascularization) as endovascular therapy strategies. Interestingly, the retrograde approach was more favorable in 7 out of these 11 included studies. Mean age of patients ranged from 58.7 to 75.2 years and the majority gender was male (71.9\%). The median NIHSS score at admission and the ASPECT score were ranged from 12 to 18 and 7 to 9 , respectively. The intracranial occlusion site is mostly located at the terminal furcation of ICA and M1 or M2 segment of MCA. The proportion of patients bridging IV tPA ranged from 27.3 to $100 \%$. Mean time of puncture to final reperfusion regarded as procedural duration spanned from 33 to $130 \mathrm{~min}$. In addition, the rate of TICI $2 \mathrm{~b}-3$ successful reperfusion and mRS 0-2 favorable outcome were $80.6 \%$ (50-92.1\%) and 43.5\% (30-71.4\%), respectively. Any procedure- and device-related complications including arterial dissection, artery perforation, clot migration, embolization in new territory, and stent deployment failure or device malfunction were reported in six studies and the incidence of any of these complications was $17.7 \%(6.5-24.9 \%)$. The incidence of sICH complication was $8.1 \%(5-16.1 \%)$, while mortality risk was $16.7 \%(6.9-32.3 \%)$.

\section{Main Outcomes Comparison Between Antegrade and Retrograde Approaches}

Meta-analysis for main outcomes of antegrade and retrograde groups is shown in Table 3 and Forest plot is given correspondingly in Figure 2. All the 11 studies provided data on the TICI $2 b-3$ representing successful reperfusion and the pooled results indicated that a slightly higher rate of successful reperfusion in the retrograde group than that in antegrade group (83.8 vs. $78.0 \%$; OR: 0.63 , 95\% CI: $0.40-0.99$, $p=0.04)$ (Figure 2A). Notably, with $I^{2}$ value more than $50 \%$ ( $\left.p=0.02, I^{2}=52 \%\right)$, high heterogeneity existed among studies. Sensitivity analysis was further performed and indicated that heterogeneity might origin from two articles published by author Maus et al. and Haussen et al., however, both were high 


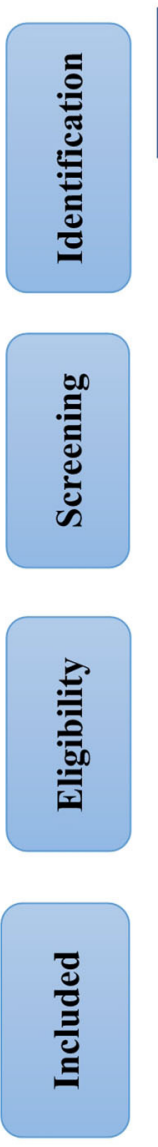

\section{Records identified through database searching $(\mathrm{n}=1907)$}

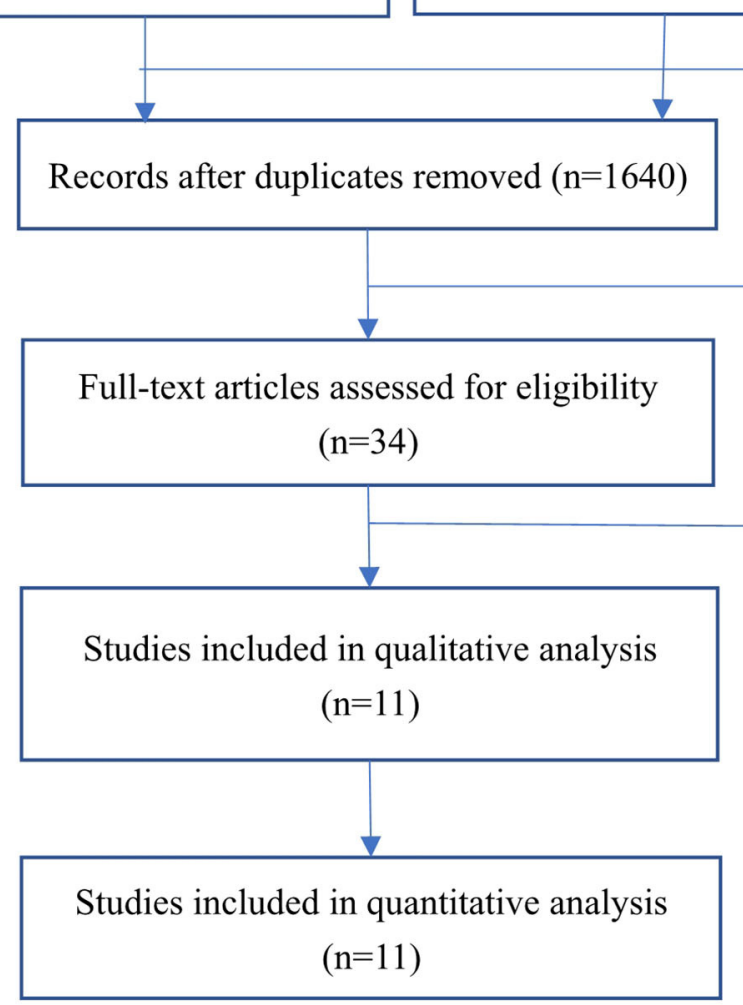

Duplicates $(\mathrm{n}=276)$

Additional records identified through other sources $(n=9)$

FIGURE 1 | Flow diagram of literature for systematic review and meta-analysis.

TABLE 1 | Characteristics of included studies.

\begin{tabular}{|c|c|c|c|c|c|c|}
\hline References & Country; Centers & $\begin{array}{l}\text { Study } \\
\text { design }\end{array}$ & $\begin{array}{l}\text { Etiology } \\
\text { (n) }\end{array}$ & $\begin{array}{l}\text { Sample } \\
\text { size }\end{array}$ & $\begin{array}{c}\text { Patients number, } \\
\text { n, AGA/RGA }\end{array}$ & $\begin{array}{l}\text { Advocated } \\
\text { strategy }\end{array}$ \\
\hline Lockau et al. (22) & Germany; Single center & $\mathrm{RC}$ & AS (24); AD (13) & 37 & $12 / 25$ & RGA \\
\hline Puri et al. (23) & USA; Multicenter & $\mathrm{RC}$ & AS (20); AD (8) & 28 & $24 / 4$ & AGA \\
\hline Moptsaris et al. (24) & Germany; Single center & $\mathrm{RC}$ & AS (52); AD (9) & 63 & $17 / 46$ & NA \\
\hline Eker et al. (14) & France; Multicenter & RPC & AS (121) & 121 & $46 / 75$ & RGA \\
\hline Maus et al. (15) & Germany; Multicenter & $\mathrm{RPC}$ & AS (144); AD (21) & 171 & $101 / 70$ & RGA \\
\hline Yang et al. (12) & China; Multicenter & $\mathrm{RC}$ & $\begin{array}{l}\text { AS (40); AD (11); } \\
\text { CE (8); other (1) }\end{array}$ & 60 & $31 / 29$ & RGA \\
\hline Luu et al. (27) & Vietnam; Single center & $\mathrm{RC}$ & NA & 17 & $10 / 7$ & RGA \\
\hline Neuberger et al. (13) & Germany; Single center & $\mathrm{RPC}$ & NA & 162 & $85 / 77$ & NA \\
\hline Park et al. (26) & Korea; Single center & $\mathrm{RC}$ & AS (76) & 76 & $56 / 20$ & NA \\
\hline Feil et al. (28) & Germany; Multicenter & $\mathrm{RPC}$ & NA & 493 & $267 / 226$ & RGA \\
\hline Haussen et al. (25) & USA; Multicenter & $\mathrm{RPC}$ & AS (289) & 289 & $182 / 107$ & RGA \\
\hline
\end{tabular}

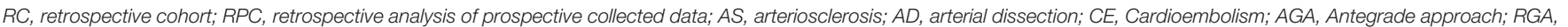
Retrograde approach; NA, not available.

quality studies, which launched by international multicenter collaborations with a relatively large sample size. At the same time, procedural duration from original literature is given in Table 2, but not enrolled ultimately in meta-analysis due to the inappropriate data type of continuous variables. Even so, seven included studies reported procedural duration. The mean time from a puncture to final reperfusion also showed a bit shorter time advantage tendency of retrograde approach at a rough estimate (retrograde: range from 33 to $123 \mathrm{~min}$ vs. antegrade: range from 36 to $130 \mathrm{~min}$ ). There was no publication 
TABLE 2 | Main baseline data of included patients.

\begin{tabular}{|c|c|c|c|c|c|c|c|}
\hline Study & Group (n) & $\begin{array}{c}\text { Age } \\
\text { (years) }\end{array}$ & $\begin{array}{c}\text { Male, } \\
\mathrm{n}(\%)\end{array}$ & $\begin{array}{l}\text { Admission } \\
\text { NIHSS }\end{array}$ & $\begin{array}{l}\text { Admission } \\
\text { ASPECTS }\end{array}$ & $\begin{array}{l}\text { IV tPA, } \\
\text { n(\%) }\end{array}$ & $\begin{array}{c}\text { Procedural } \\
\text { duration (min) }\end{array}$ \\
\hline Lockau et al. (22) & $\begin{array}{l}\text { AGA (12) } \\
\text { RGA (25) }\end{array}$ & $\begin{array}{l}64(36-89) \\
62(40-84)\end{array}$ & $\begin{array}{c}7(58.3) \\
20(80.0)\end{array}$ & $\begin{array}{l}17(3-30) \\
17(5-27)\end{array}$ & NA & $\begin{array}{c}6(50.0) \\
14(56.0)\end{array}$ & $\begin{array}{c}130.2 \pm 45.1 \\
58.6 \pm 26.1\end{array}$ \\
\hline Puri et al. (23) & $\begin{array}{l}\text { AGA (24) } \\
\text { RGA (4) }\end{array}$ & $58.7(30-83)$ & $19(67.8)$ & $18(2-28)$ & NA & $7(27.3)$ & NA \\
\hline Moptsaris et al. (24) & $\begin{array}{l}\text { AGA (17) } \\
\text { RGA (46) }\end{array}$ & $67(33-84)$ & $49(78)$ & $14(1-29)$ & NA & 33(52) & $\begin{array}{l}110(15-208) \\
125(45-212)\end{array}$ \\
\hline Eker et al. (14) & $\begin{array}{l}\text { AGA (46) } \\
\text { RGA (75) }\end{array}$ & $\begin{array}{l}70(63-79) \\
70(63-76)\end{array}$ & $\begin{array}{l}31(67.4) \\
59(78.7)\end{array}$ & $\begin{array}{l}18(13-21) \\
16(10-19)\end{array}$ & NA & NA & $\begin{array}{l}95(53-141) \\
82(61-109)\end{array}$ \\
\hline Maus et al. (15) & $\begin{array}{l}\text { AGA (101) } \\
\text { RGA (70) }\end{array}$ & $\begin{array}{l}64 \pm 12 \\
67 \pm 12\end{array}$ & $\begin{array}{l}66(65) \\
52(74)\end{array}$ & $\begin{array}{l}15 \pm 6 \\
16 \pm 6\end{array}$ & NA & $\begin{array}{l}65(64) \\
41(59)\end{array}$ & $\begin{aligned} 103 & \pm 46123 \\
& \pm 56\end{aligned}$ \\
\hline Yang et al. (12) & $\begin{array}{l}\text { AGA (31) } \\
\text { RGA (29) }\end{array}$ & $\begin{array}{l}64(60-70) \\
60(41-68)\end{array}$ & $\begin{array}{l}24(77.4) \\
27(93.1)\end{array}$ & NA & NA & $\begin{array}{c}8(25.8) \\
13(44.8)\end{array}$ & $\begin{array}{l}125(86-167) \\
116(91-179)\end{array}$ \\
\hline Luu et al. (27) & $\begin{array}{l}\text { AGA (10) } \\
\text { RGA (7) }\end{array}$ & $\begin{array}{c}70.5 \pm 10.7 \\
69.9 \pm 6.1\end{array}$ & $\begin{array}{l}10(100) \\
6(85.7)\end{array}$ & $\begin{array}{c}15.2(7-20) \\
18.6 \\
(14-24)\end{array}$ & $\begin{array}{l}7.4 \pm 0.8 \\
7.9 \pm 1.3\end{array}$ & $\begin{array}{c}3(30) \\
7(100)\end{array}$ & $\begin{array}{l}82.2 \pm 37.9 \\
55.4 \pm 15.8\end{array}$ \\
\hline Neuberger et al. (13) & $\begin{array}{l}\text { AGA (85) } \\
\text { RGA (77) }\end{array}$ & $73.3 \pm 11.5$ & $124(76.5)$ & $16(11-20)$ & NA & NA & NA \\
\hline Park et al. (26) & $\begin{array}{l}\text { AGA (56) } \\
\text { RGA (20) }\end{array}$ & $\begin{array}{l}70.5 \pm 10.9 \\
75.2 \pm 11.1\end{array}$ & $\begin{array}{l}46(82) \\
17(85)\end{array}$ & $\begin{array}{l}12(8-15) \\
13(7-15)\end{array}$ & $\begin{array}{l}8(7-10) \\
9(8-10)\end{array}$ & NA & $\begin{array}{l}36(25-55) \\
33(27-40)\end{array}$ \\
\hline Feil et al. (28) & $\begin{array}{l}\text { AGA (267) } \\
\text { RGA (227) }\end{array}$ & $\begin{array}{l}69.3 \pm 11.9 \\
67.5 \pm 11.2\end{array}$ & $\begin{array}{l}184(68.9) \\
163(71.8)\end{array}$ & $\begin{array}{c}14(9-18) \\
14(10-18)\end{array}$ & $\begin{array}{l}8(7-10) \\
8(7-10)\end{array}$ & $\begin{array}{l}145(54.3) \\
141(62.1)\end{array}$ & $\begin{array}{c}72(50-101.5) \\
53.5(36-78)\end{array}$ \\
\hline Haussen et al. (25) & $\begin{array}{l}\text { AGA (182) } \\
\text { RGA (107) }\end{array}$ & $\begin{array}{l}67.2 \pm 10.5 \\
65.9 \pm 10.5\end{array}$ & $\begin{array}{l}119(65.4) \\
68(64.2)\end{array}$ & $\begin{array}{l}15.7 \pm 5.9 \\
15.8 \pm 6.2\end{array}$ & $\begin{array}{c}8(7-10) \\
7(6-8)\end{array}$ & $\begin{array}{l}112(61.5) \\
63(58.9)\end{array}$ & $\begin{array}{c}70(50-102) \\
56(39-90)\end{array}$ \\
\hline
\end{tabular}

Data was expressed as mean $\pm S D$, median (IQR), or $n(\%)$.

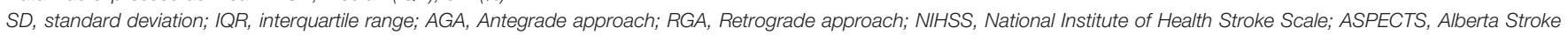
Program Early CT Score; IV TPA, intravenous tissue plasminogen activator; NA, not available.

bias according to the Begg's test $(p=0.10)$ and the Egger's test $(p=0.41)$, which is visualized in the Funnel plot (see online Supplementary File 7. Publication bias assessment).

Favorable outcome also reported by all the 11 studies and the pooled results indicated that the retrograde group achieved a significantly better 90-day functional independence than the antegrade group (47.3 vs. $40.2 \%$; OR: 0.72 , $95 \%$ CI: $0.58-$ $0.89, p=0.002$ ) (Figure 2B). Sensitivity analysis indicated the heterogeneity ( $p=0.07, I^{2}=42 \%$ ) also coming from the aforementioned two articles by Maus et al. (15) and Haussen et al. (25). No publication bias (Begg's test: $p=0.31$; Egger's test: $p=0.17$ ) was observed (see online Supplementary File 7. Publication bias assessment).

Procedure- and device-related complications were reported in six studies. Four studies provided the data on artery dissection or perforation, two studies gave the data on clot migration or embolization, and three studies demonstrated the data on stent deployment failure or device malfunction. The incidence of any procedural complication was $17.0 \%$ in the retrograde group, while the incidence of any procedural complication was $17.8 \%$ in the antegrade group. The pooled results showed that there was no significant difference between the two treatment strategies (OR: 1.04, 95\% CI: 0.74-1.45, $p=0.82$ ) (Figure 2C) and no heterogeneity ( $p=0.46, I^{2}=0 \%$ ) was observed. The incidence of any ICH complication was provided by seven studies. The pooled results indicated a tendency that the retrograde group might have a lower incidence of hemorrhage complication than the antegrade group, but this tendency was not significant (21.9 vs. $24.7 \%$; OR: 1.26, 95\% CI: $0.90-1.76, p=0.18$ ) (Figure 2D). When considering sICH, eight studies provided the relative data and pooled results showed a similar tendency (7.4 vs. $8.6 \%$; OR: 1.19, 95\% CI: 0.68-2.08, $p=0.54$ ) (Figure 2E). No inspected significant heterogeneity $\left(p=0.18, I^{2}=0 \% ; p=0.92, I^{2}=0 \%\right)$ was also there. Publication bias was not performed due to limited data with respect to these complications.

90-day mortality was reported in four studies and the incidence of mortality in the retrograde group and the antegrade group was 17.0 and $16.5 \%$, respectively. There was no remarkable difference in mortality risk between the two treatment strategies observed in pooled results (OR: 1.07, 95\% CI: 0.54-2.13, $p=0.85$ ) (Figure 2F). However, a high heterogeneity $\left(p=0.10, I^{2}=52 \%\right)$ was detected and the heterogeneity might origin from the article published by Yang et al. (12). Publication bias was not performed due to limited data.

\section{Subgroup Analyses of Outcomes Based on Heterogeneity Origin}

According to sensitivity analysis clue, we found that the publication year (before or after 2015) and ethnicity (Asian or non-Asian) might be the potential source of high heterogeneity. Subgroup analysis for outcomes of successful reperfusion between antegrade and retrograde groups was conducted by publication year or ethnicity, separately. The results showed that studies published after $2015\left(p=0.01, I^{2}=59 \%\right)$ and within 
TABLE 3 | Pooled meta-analysis outcomes of antegrade and retrograde approaches.

\begin{tabular}{|c|c|c|c|c|c|c|}
\hline Outcomes & No. of studies & AGA (\%) & RGA (\%) & OR $(95 \% \mathrm{Cl})$ & $I^{2}(\%)$ & $P$-value \\
\hline Successful reperfusion (TICl 2b-3) & 11 & 78.0 & 83.8 & $0.63(0.40-0.99)$ & 52 & 0.040 \\
\hline Favorable outcome (90-day mRS 0-2) & 11 & 40.2 & 47.3 & $0.72(0.58-0.89)$ & 42 & 0.002 \\
\hline Any $\mathrm{ICH}$ & 7 & 24.7 & 21.9 & $1.26(0.90-1.76)$ & 0 & 0.180 \\
\hline $\mathrm{sICH}$ & 8 & 8.6 & 7.4 & $1.19(0.68-2.08)$ & 0 & 0.540 \\
\hline
\end{tabular}

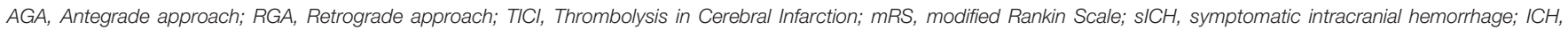
intracrinial hemorrhage; OR, odds ratio; $\mathrm{Cl}$, confidence interval; $I^{2}$, the variation attributable to heterogeneity.

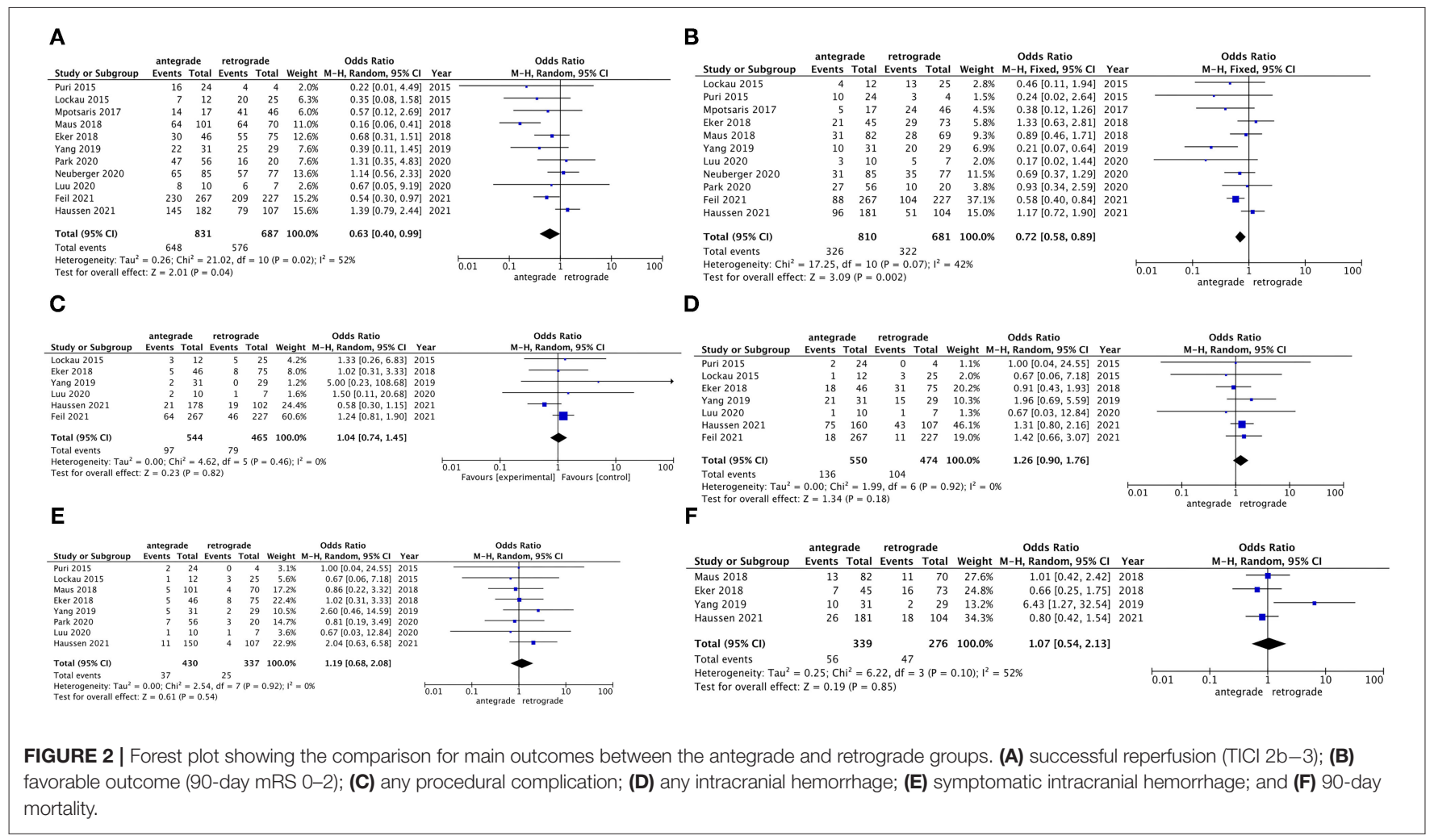

the non-Asian subgroup ( $p=0.007, I^{2}=64 \%$ ) still existed high heterogeneity (Figures 3A,B). Meanwhile, for favorable outcome, subgroup analysis result of studies published after $2015\left(p=0.04, I^{2}=50 \%\right)$ and the results within both the Asian $\left(p=0.11, I^{2}=55 \%\right)$ and non-Asian subgroups $(p=$ $0.17, I^{2}=32 \%$ ) also showed moderate-to-high heterogeneity (Figures 3C,D). Subgroup analysis of outcomes with respect to 90-day mortality and hemorrhage or procedural complications was not performed due to sensitivity analysis negative results or limited data.

\section{DISCUSSION}

This systematic review and meta-analysis compared antegrade with retrograde approaches in the treatment of AIS due to tandem lesions accounting for over 1,000 patients. Pooled results showed that the retrograde approach treating intracranial occlusion first then extracranial lesion might achieve a higher successful reperfusion rate and, thus, a better 90-day functional outcome than antegrade approach (successful reperfusion: 83.8 vs. $78.0 \%$; favorable outcome: 47.3 vs. $40.2 \%$ ). The incidence of any ICH and sICH was a statistically non-significant trend toward numerically lower in retrograde approach than that of antegrade approach (any ICH: 21.9 vs. $24.7 \%$; sICH: 7.4 vs. $8.6 \%)$. Furthermore, there was no statistical difference in either procedure-related complication rate (17.0 vs. $17.8 \%$ ) or 90 -day mortality risk (17.0 vs. $16.5 \%$ ) between the two strategies.

Tandem occlusion, including a proximal extracranial highgrade stenosis or occlusion in conjunction with a downstream intracranial occlusion, is not rare for patients with AIS. Currently, Endovascular Intervention (EVT) has been proved to be an effective technique for treating tandem occlusion 


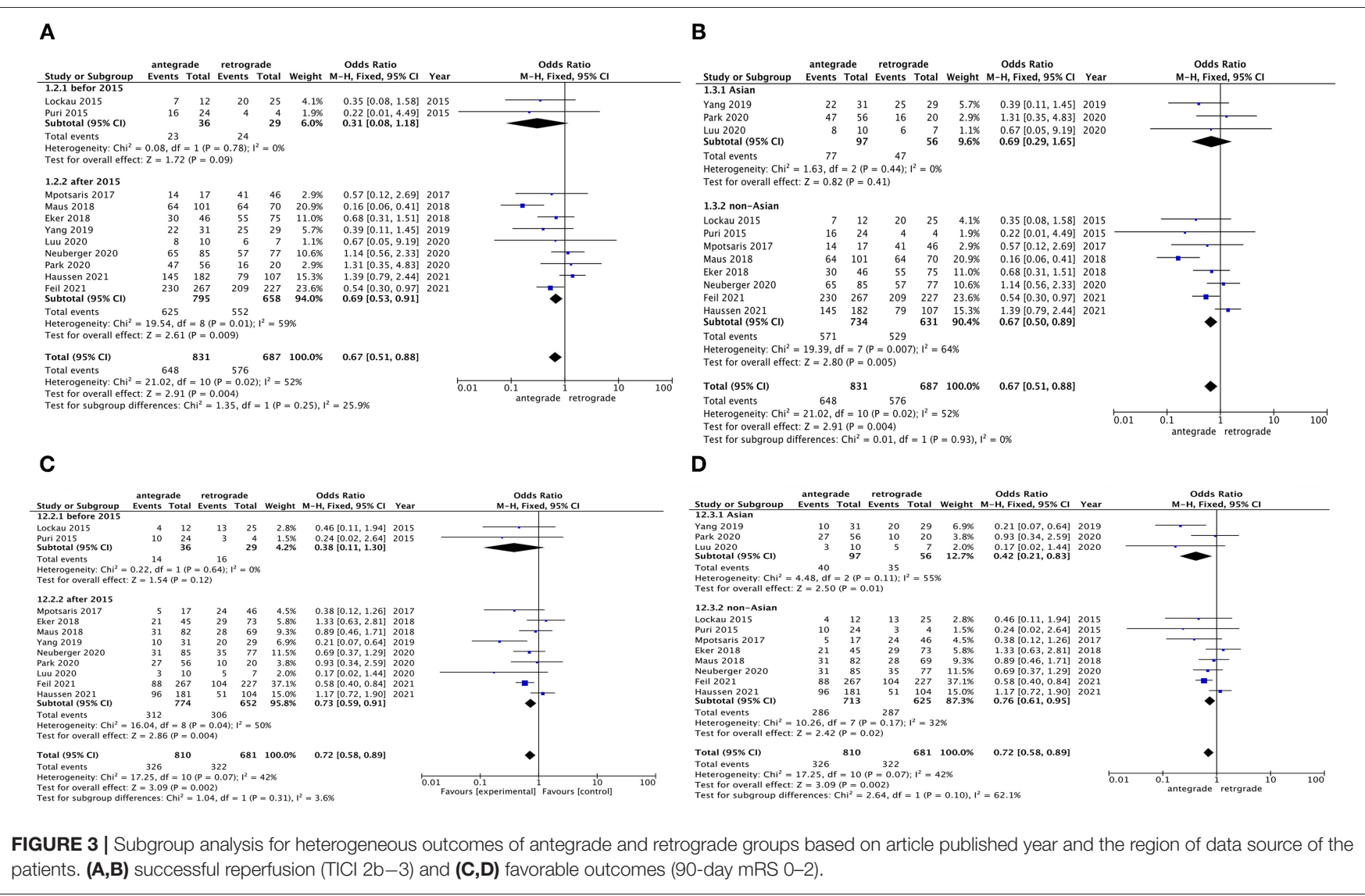

by increasing evidence (29). However, tailored evidence for the optimal treatment order between antegrade and retrograde approaches remained inconsistent and contradictory among studies, as both the approaches have innate advantages and disadvantages. The advantage of the antegrade approach is to provide blood flow to the non-occluded arteries and prevents possible recurrent occlusion of the intracranial vessels due to slow or stagnant flow. Also, it may allow bigger guide catheters for safer access to distal lesions. During distal clot removal with stent retrievers, interventionalist can easier advance the balloon guide catheter for proximal "flow arrest." In some extreme cases where the retrograde approach is not feasible due to high-grade stenosis, the antegrade approach seems to be the only choice. The major disadvantage of the retrograde approach is that intracranial thrombectomy prior to extracranial occlusion treatment may expose patients to the potential higher risk of distal embolism, especially when lacking the use of distal protection devices. However, there are opposite results showing that even a higher rate of distal embolism occurred in the antegrade approach (15). This might be explained by that foreword blood flow restoration after proximal occlusion relief increased pressure on intracranial thrombus, which resulted in clot fragments into distal terminal vessel branches. Additionally, the antegrade approach treating cervical stenosis or occlusion first might delay the intracranial reperfusion due to timeconsuming. In the contrast, the advantage of the retrograde approach is a quicker restoration of cerebral blood flow to the intracranial ischemia area and hypothetically can reduce cerebral ischemia.

Our finding suggested that the retrograde approach might be superior to the antegrade approach with respect to more and earlier blood restoration and better functional outcome achievable. This was in line with several recent large sample size multicenter studies demonstrating faster distal occlusion reperfusion consistently in better clinical outcomes with the retrograde approach $(25,28)$. Primarily, revascularization of the proximal extracranial lesion with Percutaneous Endovascular Angioplasty (PTA) and/or stenting before distal intracranial occlusion treatment seemed to be time-consuming thus postponed intracranial reperfusion. This disadvantage could be avoided in the retrograde approach. Once the microwire and catheter could navigate through the proximal artery lesion segment without difficulty, intracranial thrombectomy was conducted immediately that would shorten the ischemic time of attacked brain territory. Another possible reason was owing to the rapid development of new thrombectomy devices represented by stent retriever and large bore suction bolt catheter. Compared to older devices, the new generation devices could reduce the technical difficulty and guarantee to achieve a higher reperfusion rate at the shorter procedural time (30). Nevertheless, the higher rate of successful reperfusion with the retrograde approach seems hard to explain and needs to be further tested. There have been 
studies showing time-dependent clot composition changes and there is possible preferential degradation of the erythrocyte-rich part of the clot in the early stage. Delayed thrombectomy is, thus, more likely to face the clots with a higher proportion of fibrin and platelets, which are associated with later passes of thrombectomy and, thus, increase the difficulty of reperfusion (31). Retrograde approach may help to decrease the risk of clot distal embolism by flushing out the small thrombi with primarily restored intracranial foreword blood flow during extracranial occlusion treatment.

A higher favorable outcome rate was another important observation in this study, with putative beneficial from a higher rate of successful reperfusion. Successful reperfusion after acute large vessel occlusive stroke was a robust predictor associated with good clinical outcomes (32). For AIS due to tandem occlusions, distal vascular revascularization may be more important than the proximal lesion processing. Thus, the treatment order of the retrograde approach allowed the intracranial offending vessel to gain rapid reperfusion contributing to the anoxia and ischemic brain tissue rescue in the affected territory. Early reperfusion shortens the ischemic duration and could bring more beneficial for poor or not yet established leptomeningeal collateral circulation in the acute phase of stroke. This might be the partially pathophysiologic explanation for favorable functional independence corresponding to successful reperfusion. Moreover, extracranial stent angioplasty prior to intracranial thrombectomy was hypothesized to increase additional procedure- and device-related complications due to scratching between thrombectomy device and carotid stent struts, especially in case of advancing resistance $(33,34)$. Retrograde approach, through adopting the intracranial first strategy, could shun these potential risks associated with deteriorating clinical outcomes.

Concerning the safety profile between antegrade and retrograde approaches, our meta-analysis showed no statistic differences in terms of procedural or hemorrhagic complications as well as 90-day mortality, except for the trend toward a lower rate of any $\mathrm{ICH}$ and $\mathrm{sICH}$ in patients treated with the retrograde approach. In the latest large sample size registry study, a comparison of intracranial- and extracranial-first approaches in more than 600 patients demonstrated no statistical differences in periprocedural complications, but a slightly lower incidence of periprocedural complications with the intracranial-first approach (28). Our results were in line with this study and other previous reports $(12,25)$. However, our results were inconsistent with the respective analysis demonstrating retrograde approach had higher periprocedural complications than antegrade approach (23), but the results were based on small sample size and heterogeneous populations. A previous meta-analysis observed no statistic differences of outcomes parameters and safety profiles between intracranial- and extracranial-first group, except for a slightly lower procedure-related complication (11). The optimal technical approach still needs clarification in prospective studies with meticulous design, although related RCT seems to be impractical.

This study has some limitations. First, we could not rule out the inherent risk of selection bias due to respective observational design, despite approximately a half of studies coming from prospective collected database. Heterogeneity among studies might be inevitable, thus subgroup analysis was performed on putative heterogeneity derivations. Also, several outcomes were not enrolled in meta-analysis due to the inappropriate type such as continuous variables or data limited. There were rare literature specifying cervical stenosis vs. complete occlusion with respect to its impact on revascularization strategies and pathophysiology, so that the inadequate data prevented a metaanalysis from being performed, as cases with extremely severe stenosis may influence the decision of revascularization strategies and probably lead to a bias of the final outcomes. A similar condition existed with respect to distal embolization. However, the strengths of this meta-analysis are recruiting studies with a direct comparison of the two approaches. There are several studies with multicenter design and large sample size. Compared to the previous meta-analysis, this study will provide updated clinical evidence of strategy selection and decision-making for AIS with tandem occlusions and will definitely be helpful in guiding future clinical trials.

\section{CONCLUSION}

In conclusion, for AIS due to tandem occlusions, the retrograde approach might achieve a higher successful reperfusion rate and better favorable functional outcome with a comparable safety profile when compared with the antegrade approach. Further prospective controlled studies with more meticulous design and a higher level of evidence are warranted.

\section{DATA AVAILABILITY STATEMENT}

The original contributions presented in the study are included in the article/Supplementary Material, further inquiries can be directed to the corresponding authors.

\section{AUTHOR CONTRIBUTIONS}

$\mathrm{XB}$ and $\mathrm{LJ}$ contributed to the initial idea for this study. XM, TWe, $\mathrm{XZ}, \mathrm{WH}$, and TWa developed and revised the search strategy. $\mathrm{XM}, \mathrm{XB}, \mathrm{XZ}, \mathrm{XW}$, and JD completed the study design. WC and $\mathrm{LJ}$ contributed to consults about clinical issues. YF and $\mathrm{XZ}$ extracted the data. $\mathrm{KY}$ analyzed the extraction data. XM, XZ, and $\mathrm{XB}$ contributed to the original draft. XB, XX, TY, WC, and LJ contributed to the revision of the draft. XM and JD qualitatively evaluated the risk of publication bias. All authors approved the final manuscript prior to submission.

\section{FUNDING}

This study was supported by the Natural Science Foundation of China (No. 81960219) and the Clinical Research Project of the Second Affiliated Hospital of Kunming Medical University (No. 2020ynlc009).

\section{SUPPLEMENTARY MATERIAL}

The Supplementary Material for this article can be found online at: https://www.frontiersin.org/articles/10.3389/fneur. 2021.757665/full\#supplementary-material 


\section{REFERENCES}

1. Goyal M, Menon BK, van Zwam WH, Dippel DW, Mitchell PJ, Demchuk AM, et al. Endovascular thrombectomy after large-vessel ischaemic stroke: a metaanalysis of individual patient data from five randomised trials. Lancet. (2016) 387:1723-31. doi: 10.1016/S0140-6736(16)00163-X

2. Grau AJ, Weimar C, Buggle F, Heinrich A, Goertler M, Neumaier S, et al. Risk factors, outcome, and treatment in subtypes of ischemic stroke: the German stroke data bank. Stroke. (2001) 32:2559-66. doi: 10.1161/hs1101. 098524

3. Rubiera M, Ribo $M$, Delgado-Mederos R, Santamarina E, Delgado $\mathrm{P}$, Montaner J, et al. Tandem internal carotid artery/middle cerebral artery occlusion: an independent predictor of poor outcome after systemic thrombolysis. Stroke. (2006) 37:23015. doi: 10.1161/01.STR.0000237070.80133.1d

4. Christou I, Felberg RA, Demchuk AM, Burgin WS, Malkoff M, Grotta JC, et al. Intravenous tissue plasminogen activator and flow improvement in acute ischemic stroke patients with internal carotid artery occlusion. $J$ Neuroimaging. (2002) 12:119-23. doi: 10.1111/j.1552-6569.2002.tb0 0107.x

5. Berkhemer OA, Fransen PS, Beumer D, van den Berg LA, Lingsma HF, Yoo AJ, et al. A randomized trial of intraarterial treatment for acute ischemic stroke. N Engl J Med. (2015) 372:11-20. doi: 10.1056/NEJMoa14 11587

6. Campbell BC, Mitchell PJ, Kleinig TJ, Dewey HM, Churilov L, Yassi N, et al. Endovascular therapy for ischemic stroke with perfusion-imaging selection. N Engl J Med. (2015) 372:1009-18. doi: 10.1056/NEJMoal 414792

7. Papanagiotou P, Haussen DC, Turjman F, Labreuche J, Piotin M, Kastrup A, et al. Carotid stenting with antithrombotic agents and intracranial thrombectomy leads to the highest recanalization rate in patients with acute stroke with tandem lesions. JACC Cardiovasc Interv. (2018) 11:12909. doi: 10.1016/j.jcin.2018.05.036

8. Sadeh-Gonik U, Tau N, Friehmann T, Bracard S, Anxionnat R, Derelle AL, et al. Thrombectomy outcomes for acute stroke patients with anterior circulation tandem lesions: a clinical registry and an update of a systematic review with meta-analysis. Eur J Neurol. (2018) 25:693700. doi: $10.1111 /$ ene. 13577

9. Zhu F, Bracard S, Anxionnat R, Derelle AL, Tonnelet R, Liao L, et al. Impact of emergent cervical carotid stenting in tandem occlusion strokes treated by thrombectomy: a review of the TITAN collaboration. Front Neurol. (2019) 10:206. doi: 10.3389/fneur.2019.00206

10. Anadani M, Spiotta AM, Alawieh A, Turjman F, Piotin M, Haussen DC, et al. Emergent carotid stenting plus thrombectomy after thrombolysis in tandem strokes: analysis of the TITAN registry. Stroke. (2019) 50:22502. doi: 10.1161/STROKEAHA.118.024733

11. Wilson MP, Murad MH, Krings T, Pereira VM, O'Kelly C, Rempel J, et al. Management of tandem occlusions in acute ischemic stroke - intracranial versus extracranial first and extracranial stenting versus angioplasty alone: a systematic review and meta-analysis. J Neurointerv Surg. (2018) 10:7218. doi: 10.1136/neurintsurg-2017-013707

12. Yang D, Shi Z, Lin M, Zhou Z, Zi W, Wang H, et al. Endovascular retrograde approach may be a better option for acute tandem occlusions stroke. Interv Neuroradiol. (2019) 25:194-201. doi: 10.1177/1591019918805140

13. Neuberger U, Moteva $K$, Vollherbst $D F$, Schönenberger $S$, Reiff $T$, Ringleb PA, et al. Tandem occlusions in acute ischemic stroke impact of antithrombotic medication and complementary heparin on clinical outcome and stent patency. J Neurointerv Surg. (2020) 12:108893. doi: 10.1136/neurintsurg-2019-015596

14. Eker OF, Bühlmann M, Dargazanli C, Kaesmacher J, Mourand I, Gralla $\mathrm{J}$, et al. Endovascular treatment of atherosclerotic tandem occlusions in anterior circulation stroke: technical aspects and complications compared to isolated intracranial occlusions. Front Neurol. (2018) 9:1046. doi: 10.3389/fneur.2018.01046

15. Maus V, Borggrefe J, Behme D, Kabbasch C, Abdullayev N, Barnikol UB, et al. Order of treatment matters in ischemic stroke: mechanical thrombectomy first, then carotid artery stenting for tandem lesions of the anterior circulation. Cerebrovasc Dis. (2018) 46:59-65. doi: 10.1159/000492158
16. Rodrigues M, Cunha A, Figueiredo S, Carvalho A, Veloso M, Barros P, et al. Emergent carotid artery stenting in atherosclerotic disease of the internal carotid artery with tandem intracranial occlusion. J Neurol Sci. (2018) 387:196-8. doi: 10.1016/j.jns.2018.02.034

17. Shamseer L, Moher D, Clarke M, Ghersi D, Liberati A, Petticrew M, et al. Preferred reporting items for systematic review and meta-analysis protocols (PRISMA-P) 2015: elaboration and explanation. BMJ. (2015) 350:g7647. doi: 10.1136/bmj.g7647

18. Hacke W, Kaste M, Fieschi C, von Kummer R, Davalos A, Meier D, et al. Randomised double-blind placebo-controlled trial of thrombolytic therapy with intravenous alteplase in acute ischaemic stroke (ECASS II). Second European-Australasian Acute Stroke Study Investigators. Lancet. (1998) 352:1245-51. doi: 10.1016/s0140-6736(98)08020-9

19. Higgins JP, Thompson SG, Deeks JJ, Altman DG. Measuring inconsistency in meta-analyses. BMJ. (2003) 327:557-60. doi: 10.1136/bmj.327.7414.557

20. Lo CK, Mertz D, Loeb M. Newcastle-Ottawa scale: comparing reviewers' to authors' assessments. BMC Med Res Methodol. (2014) 14:45. doi: 10.1186/1471-2288-14-45

21. Sterne JA, Sutton AJ, Ioannidis JP, Terrin N, Jones DR, Lau J, et al. Recommendations for examining and interpreting funnel plot asymmetry in meta-analyses of randomised controlled trials. BMJ. (2011) 343:d4002. doi: 10.1136/bmj.d4002

22. Lockau H, Liebig $T$, Henning $T$, Neuschmelting V, Stetefeld $H$, Kabbasch C, et al. Mechanical thrombectomy in tandem occlusion: procedural considerations and clinical results. Neuroradiology. (2015) 57:589-98. doi: 10.1007/s00234-014-1465-5

23. Puri AS, Kühn AL, Kwon HJ, Khan M, Hou SY, Lin E, et al. Endovascular treatment of tandem vascular occlusions in acute ischemic stroke. $J$ Neurointerv Surg. (2015) 7:158-63. doi: 10.1136/neurintsurg-2013-011010

24. Mpotsaris A, Kabbasch C, Borggrefe J, Gontu V, Soderman M. Stenting of the cervical internal carotid artery in acute stroke management: The Karolinska experience. Interv Neuroradiol. (2017) 23:159-65. doi: 10.1177/1591019916681983

25. Haussen DC, Turjman F, Piotin M, Labreuche J, Steglich-Arnholm H, Holtmannspötter M, et al. Head or Neck First? Speed and rates of reperfusion in thrombectomy for tandem large vessel occlusion strokes. Interv Neurol. (2020) 8:92-100. doi: 10.1159/000496292

26. Park JS, Lee JM, Kwak HS, Chung GH. Endovascular treatment of acute carotid atherosclerotic tandem occlusions: Predictors of clinical outcomes as technical aspects and location of tandem occlusions. J Stroke Cerebrovasc Dis. (2020) 29:105090. doi: 10.1016/j.jstrokecerebrovasdis.2020.105090

27. Vu-Dang L, Nguyen QA, Nguyen-Thi-Thu T, Tran AT, Le-Chi C, Le-Hoang $\mathrm{K}$, et al. Endovascular treatment for acute tandem occlusion stroke: results from case series of 17 patients. Ann Indian Acad Neurol. (2020) 23:7883. doi: 10.4103/aian.AIAN_464_18

28. Feil K, Herzberg M, Dorn F, Tiedt S, Küpper C, Thunstedt DC, et al. Tandem lesions in anterior circulation stroke: analysis of the German stroke registry-endovascular treatment. Stroke. (2021) 52:126575. doi: 10.1161/STROKEAHA.120.031797

29. Sivan-Hoffmann R, Gory B, Armoiry X, Goyal M, Riva R, Labeyrie PE, et al. Stent-retriever thrombectomy for acute anterior ischemic stroke with tandem occlusion: a systematic review and meta-analysis. Eur Radiol. (2017) 27:247-54. doi: 10.1007/s00330-016-4338-y

30. Yoon W, Baek BH, Lee YY, Kim SK, Kim JT, Park MS. Association of pretreatment pontine infarction with extremely poor outcome after endovascular thrombectomy in acute basilar artery occlusion. J Neurointerv Surg. (2021) 13:136-40. doi: 10.1136/neurintsurg-2020-015930

31. Pikija S, Magdic J, Trkulja V, Unterkreuter P, Mutzenbach JS, Novak HF, et al. Intracranial thrombus morphology and composition undergoes timedependent changes in acute ischemic stroke: A CT densitometry study. Int $J$ Mol Sci. (2016) 17:1959. doi: 10.3390/ijms17111959

32. Vanacker P, Lambrou D, Eskandari A, Maeder P, Meuli R, Ntaios $\mathrm{G}$, et al. Improving prediction of recanalization in acute large-vessel occlusive stroke. J Thromb Haemost. (2014) 12:814-21. doi: 10.1111/jth. 12561

33. Akpinar S, Gelener P. Endovascular treatment of acute tandem occlusion strokes and stenting first experience. J Clin Neurosci. (2018) 47:32831. doi: 10.1016/j.jocn.2017.09.010 
34. Lescher S, Czeppan K, Porto L, Singer OC, Berkefeld J. Acute stroke and obstruction of the extracranial carotid artery combined with intracranial tandem occlusion: results of interventional revascularization. Cardiovasc Intervent Radiol. (2015) 38:304-13. doi: 10.1007/s00270-014-1047-2

Conflict of Interest: The authors declare that the research was conducted in the absence of any commercial or financial relationships that could be construed as a potential conflict of interest.

Publisher's Note: All claims expressed in this article are solely those of the authors and do not necessarily represent those of their affiliated organizations, or those of the publisher, the editors and the reviewers. Any product that may be evaluated in this article, or claim that may be made by its manufacturer, is not guaranteed or endorsed by the publisher.

Copyright (๑ 2022 Min, Du, Bai, Wei, Dmytriw, Patel, Zhang, Xu, Feng, Wang, Wang, Yang, Hu, Yi, Chen and Jiao. This is an open-access article distributed under the terms of the Creative Commons Attribution License (CC BY). The use, distribution or reproduction in other forums is permitted, provided the original author(s) and the copyright owner(s) are credited and that the original publication in this journal is cited, in accordance with accepted academic practice. No use, distribution or reproduction is permitted which does not comply with these terms. 